\begin{tabular}{|llc|}
\hline & & $E-I S S N:$ \\
& Jurnal Pendidikan Matematika dan Matematika & $2656-5846$ \\
VYGOTSKY & Program Studi Pendidikan Matematika & P-ISSN: \\
& Fakultas Keguruan dan Ilmu Pendidikan & $2656-2286$ \\
& Universitas Islam Lamongan & Vol. 2(2) \\
& http://jurnalpendidikan.unisla.ac.id/index.php/VoJ & Agustus 2020 \\
& & pp.90-101 \\
\hline \hline
\end{tabular}

\title{
ANALISIS VARIAN SEDERHANA DAN UJI-SCHEFFE DALAM PENELITIAN EKSPERIMEN PENGAJARAN MATEMATIKA MELALUI PEMAHAMAN FILSAFAT MATEMATIKA
}

\author{
(SIMPLE VARIANT ANALYSIS AND SCHEFFE TEST IN RESEARCH \\ EXPERIMENTS IN TEACHING MATHEMATICS THROUGH \\ UNDERSTANDING OF MATHEMATICAL PHILOSOPHY)
}

\section{Endro Tri Susdarwono ${ }^{1}$}

1Universitas Peradaban, saniscara99midas@gmail.com

\begin{tabular}{l}
\hline \hline Info Artikel \\
\hline Received Jul 1, 2020 \\
Revised Aug 3, 2020 \\
Accepted Aug 29, 2020 \\
\hline Kata Kunci: \\
Analisis varian \\
Penelitian Eksperimen \\
Filsafat Matematika \\
Matematika \\
Uji-Scheffe
\end{tabular}

\section{Cara merujuk artikel ini:}

Susdarwono, E.T. (2020). Analisis Varian Sederhana dan Uji-Scheffe dalam Penelitian Eksperimen Pengajaran Matematika melalui Pemahaman Filsafat Matematika. Vygotsky: Jurnal Pendidikan Matematika dan Matematika, 2 (2), pp. 90-101. Diunduh dari http://jurnalpendidikan. unisla.ac.id/index.php/ VoJ/article/view/240/pdf

\begin{abstract}
This study aims to examine the differences in teaching mathematics by using an understanding of mathematical philosophy towards the value of mathematical problems that are classified as difficult categories. In this research the method used is experiment. The results of this experimental study revealed that with analysis of variance there was a significant difference between the group meanes, namely group 1 as a control variable, group 2 as an experimental variable with a half-semester of mathematics teaching with a mathematical philosophy model and group 3 as an experimental variable with a length of one the mathematics teaching semester using the mathematical philosophy model and through the scheffe test concluded that the experimental group performed significantly better than the control group.

\begin{tabular}{l}
\hline Abstrak \\
Penelitian ini bertujuan untuk menguji beda \\
pengajaran matematika dengan menggunakan \\
pemahaman filsafat matematika terhadap nilai soal \\
matematika yang tergolong kategori sulit. Dalam \\
penelitian ini metode yang digunakan adalah \\
eksperimen. Pengujian yang digunakan dengan \\
memakai analisis varians sederhana dan uji scheffe. \\
Hasil penelitian eksperimen ini mengungkapkan \\
bahwa dengan analis varians ada beda yang \\
signifikan antara mean-mean kelompok, yaitu \\
kelompok 1 sebagai variabel control, kelompok 2 \\
sebagai variabel eksperimen dengan lama setengah \\
semester pengajaran matematika dengan model \\
filsafat matematika dan kelompok 3 sebagai variabel \\
eksperimen dengan lama satu semester pengajaran \\
matematika dengan model filsafat matematika serta \\
melalui uji scheffe disimpulkan bahwa kelompok \\
eksperimen secara signifikan bepenampilan lebih baik \\
dibandingkan kelompok control.
\end{tabular}
\end{abstract}

Copyright () 2020 Vygotsky: Jurnal Pendidikan Matematika dan Matematika. All right reserved 


\section{PENDAHULUAN}

Mengapa harus belajar matematika? Tentu saja, pada tahap-tahap dasar, saat kita belajar perhitungan dasar seperti penjumlahan, pengurangan, perkalian dan pembagian, tak terlalu sulit bagi kebanyakan kita untuk memahami alasan dari mempelajari semua itu. Kita membutuhkan kemampuan-kemampuan perhitungan sederhana semacam itu agar kita bisa menghitung secara tepat berapa jumlah uang yang harus kita keluarkan saat membeli 2 kilogram beras, berapa total ongkos perjalanan kita dari rumah kita ke tempat tujuan yang mau kita capai, berapa uang kembalian yang harus kita terima jika kita membeli 5meter kain dengan menggunakan uang 100 ribuan dan sebagainya. Intinya, dalam kehidupan sehari-hari, ada sekian banyak konteks di mana kemampuan-kemampuan berhitung sederhana semacam itu sangatlah dibutuhkan, dan mau tak mau kita harus menguasainya agar kita tak tertipu dalam kehidupan kita. Tapi bagaimana dengan perhitunganperhitungan seperti menghitung sinus, limit, logaritma dan sebagainya? Untuk apa kita harus belajar semua itu?

Pentingnya belajar matematika dikuatkan oleh Cockroft (Martini, et. $\mathrm{Al}, 2018)$ antara lain: (1) dalam kehidupan sehari-hari sering digunakan; (2) semua bidang studi memerlukan keterampilan matematika yang sesuai dengan bidangnya; (3) sarana komunikasi; (4) digunakan untuk menyajikan informasi dengan berbagai cara; dan (5) meningkatkan kepuasan terhadap usaha.

Walaupun matematika sangat penting untuk dipelajari dan dikuasai siswa, namun tidak dapat dipungkiri bahwa matematika memiliki sifat abstrak yang menjadi salah satu sebab matematika sulit untuk dipahami siswa (Yenni \& Sukmawati, 2019). Oleh karena itu, siswa perlu diberikan pemahaman tentang pentingnya arti belajar, manfaat belajar, bagaimana mencapainya, sehingga siswa akan mengerti tentang kegunaan materi pelajaran maematika dalam kehidupannya (Zakiah, et.al, 2019). Menurut Irmawati et.al (2019) untuk mempelajari matematika tidaklah cukup hanya mengenal konsep, namun dapat menggunakan konsep tersebut untuk menyelesaikan masalah, baik massalah yang ada kaitannya dengan matematika maupun permasalahan yang dijumpai dalam kehidupan sehari-hari.

Salah satu sebab utama dari kesulitan memahami matematika ialah karena sifatnya yang abstrak. Hal ini sangat kontras dengan alam pikiran kebanyakan dari kita yang terbiasa berpikir tentang obyek-obyek yang konkret. Bahasa matematika adalah bahasa yang abstrak, bahasa yang dipenuhi dengan begitu banyak perlambang. Karena sifatnya yang abstrak inilah, seringkali kebanyakan orang awam mengira bahwa matematika itu taka ada hubungannya dengan dunia nyata yang konkret. Orang menyangka bahwa matematika itu berhubungan dngan dunia lain, dunia yang sama sekali berbeda sifatnya dengan dunia kita yang nyata ini. Operasi perhitungan matematis yang tertentu, seperti penjumlahan, pengurangan, perkalian dan pembagian, memang berguna dalam 
kehidupan kita sehari-hari. Namun konsep-konsep matematika yang lain, semisal logaritma, kalkulus dan sebagainya, sungguh tak kita pahami apa kaitannya dengan dunia kita yang nyata (Alisah \& Dharmawan, 2007).

Apakah hakikat dari matematika itu sesungguhnya? Mengapa umat manusia mengembangkan dan menyusun hukum-hukum perhitungan matematika dalam kehidupannya? Tidakkah cukup hidup ini hanya sekedar bekerja, mendapatkan uang, membesarkan anak, dan menikmati hari tua dengan santai? Mengapa harus ada matematika? Untuk apa maematika itu sesungguhnya? Dengan merenungkan berbagai kutipan dari para pemikir besar dunia matematika akan berguna sebagai batu loncatan untuk menemukan jawaban atas pertanyaan tersebut, yang pada akhirnya mampu memahami pengajaran matematika menggunakan filsafat matematika.

\section{METODE PENELITIAN}

Metode penelitian adalah cara alamiah untuk memperoleh data dengan kegunaan dan tujuan tertentu (Lestari \& Yudhanegara, 2012). Terdapat berbagai macam metode penelitian. Dalam penelitian ini metode yang digunakan adalah eksperimen. Metode eksperimen adalah suatu metode penelitian yang berusaha mencari hubungan variabel tertentu terhadap variabel lain dalam kondisi yang terkontrol secara ketat (Sugiyono, 2003).

Secara umum, karakteristik penelitian eksperimen dalam penelitian ini meliputi:

1. Manipulasi

Peneliti memanipulasi variabel bebas dengan memberikan perlakuan.

Perlakuan tersebut bertujuan agar apa yang diharapkan peneliti dalam penelitian dapat tercapai. Variabel bebas yang dimanipulasi dalam penelitian ini adalah model atau metode pembelajaran yakni menggunakan pengajaran matematika melalui filsafat matematika.

2. Pengendalian atau kontrol

Pengendalian atau control dilakukan dengan menambahkan faktor lain atau menambahkan faktor lain yang tidak diinginkan peneliti dari variabel yang diteliti. Faktor lain tersebut disebut juga sebagai variabel control. Variabel control ini dikendalikan dan dibuat konstan sehingga pengaruh variabel independent terhadap dependen tidak dipengaruhi faktor lain yang tidak diteliti. Pada desain penelitian eksperimen ini, variabel control berupa kelas control, yaitu kelas yang dijadikan sebagai pembanding dan tidak mendapatkan perlakuan seperti pada kelas eksperimen.

3. Pengamatan

Setelah perlakuan diberikan selama kurun waktu tertentu, peneliti melakukan pengamatan atau pengukuran untuk mengetahui pengaruh dari manipulasi/perlakuan yang diberikan terhadap variabel yang diteliti. Pengamatan dilakukan melalui pengumpulan data berupa tes. 


\section{Desain Penelitian}

Desain kuantitatif yang akan digunakan dalam penelitian ini berupa desain penelitian eksperimen the randomized posttest only control group using matched subject (Lestari et al, 2015). Pada desain gambar 1 mengilustrasikan, terdapat tiga kelompok yang masing-masing dipilih secara acak dengan pencocokan subjek (random assignment with matching subject), disimbolkan dengan $\mathrm{M}_{\mathrm{r}}$. Cara ini dilakukan sebagai upaya untuk meningkatkan kemungkinan, bahwa kelompok subjek dalam penelitian tersebut ekuivalen. Pencocokan subjek tersebut dilakukan dengan cara memasangkan individu-individu berdasarkan kriteria tertentu. Kriteria tersebut ditentukan berdasarkan teori, dan pengalaman peneliti. Teori yang digunakan sebagai dasar pemahaman individu menggunakan teori Vorstellungen dari Herbert.

\begin{tabular}{|c|c|c|}
\hline $\begin{array}{l}\text { Penentuan sampel secara acak dengan } \\
\text { pencocokan subyek (random assignment } \\
\text { with matching subject), untuk memperoleh } \\
\text { kelompok yang ekuivalen }\end{array}$ & $\begin{array}{l}\text { Model pengajaran } \\
\text { matematika dengan } \\
\text { filsafat matematika }\end{array}$ & $\begin{array}{l}\text { Postes untuk mengukur } \\
\text { kemampuan akhir } \\
\text { memahami dan } \\
\text { menyelesaikan soal sulit }\end{array}$ \\
\hline $\begin{array}{l}\text { Penentuan sampel secara acak dengan } \\
\text { pencocokan subyek (random assignment } \\
\text { with matching subject), untuk } \\
\text { memperoleh kelompok yang ekuivalen }\end{array}$ & $\begin{array}{l}\text { Kontrol terhadap } \\
\text { perlakuan dengan } \\
\text { menerapkan } \\
\text { pembelajraan yang } \\
\text { biasanya dilakukan. }\end{array}$ & $\begin{array}{l}\text { Postes untuk mengukur } \\
\text { kemampuan akhir } \\
\text { memahami dan } \\
\text { menyelesaikan soal sulit }\end{array}$ \\
\hline
\end{tabular}

Gambar 1. Desain Penelitian Eksperimen The Randomized Posttest Only Control Group Using Matched Subject Design

Setelah peneliti memasangkan individu-individu yang ekuivalen selanjutnya peneliti memisahkan tiap pasangan individu ke dalam kelompok yang berbeda. Dengan demikian, akan diperoleh dua kelompok yang setara. Kelompok kedua dan ketiga diberi perlakuan (X) dan kelompok pertama tidak diberi perlakuan $X$, sebagai control terhadap perlakuan. Kelompok yang diberi perlakuan disebut kelompok eksperimen dan kelompok yang tidak diberi perlakuan disebut kelompok control. Kemudian, ketiga kelompok diberi postes $(\mathrm{O})$. teknik sampling yang cocok digunakan untuk desain ini adalah simple random sampling yang dikombinasikan dengan purposive sampling. Sampel diambil dari siswa di SMK Texmaco Pemalang. Berikut ini ilustrasi cara penentuan sampel secara acak dengan pencocokan subjek (random assignment with matching subject):

Setelah terbentuk dua kelompok yang ekuivalen, peneliti menjadikan kelompok dua sebagai kelompok eksperimen, yaitu kelompok yang mendapatkan perlakuan model pengajaran matematika melalui filsafat matematika dengan durasi waktu setengah semester, kelompok tiga sebagai kelompok eksperimen, yaitu kelompok yang mendapatkan 
perlakuan model pengajaran matematika melalui filsafat matematika dengan durasi waktu satu semester, sedangkan kelompok satu dijadikan sebagai kelompok control, yaitu kelompok yang mendapatkan pengajaran matematika yang biasa dilakukan sebelumnya, model pembelajaran langsung. Setelah kurun waktu satu semester, ketiga kelompok diberikan postes mengenai kemampuan memahami dan menyelesaikan soal matematika yang tergolong sulit dengan bentuk tes yang sama.

\section{HASIL DAN PEMBAHASAN}

Penelitian ini bertujuan untuk menguji beda pengajaran matematika dengan menggunakan pemahaman filsafat matematika terhadap nilai soal matematika yang tergolong kategori sulit. Pengujian yang digunakan dengan memakai analisis varians sederhana dan uji schefe, namun sebelum uji dapat dilaksanakan data harus diuji dulu apakah berasal dari sampel yang homogen menggunakan uji homogenitas. Uji homogenitas dimaksudkan untuk memperlihatkan bahwa kelompok atau lebih data sampel berasal dari populasi yang memiliki variansi yang sama.

Hipotesis yang diuji adalah:

$\mathrm{H}_{0}: \tau_{1}^{2}=\tau_{2}^{2}=\tau_{\mathrm{s}}^{2}$

$\mathrm{H}_{1}$ : salah satu tanda $=$ tidak berlaku $($ ada yang $\neq)$

Teknik pengujian yang digunakan adalah uji Bartlet, dilakukan dengan menghitung $X_{\text {hitung }}^{2}$ dan membandingkan dengan $X_{\text {tabel }}^{2}$. Bila $X_{\text {hitung }}^{2} \leq X_{\text {tabel }}^{2}$ maka hipotesis nol diterima, artinya data berasal dari populasi homogen.

Berikut ini disajikan uji homogenitas data dari penelitian. Suatu penelitian akan membandingkan tingkat penguasaan siswa terhadap pemahaman soal yang sulit berdasarkan lamanya belajar menggunakan metode pemberian filsafat matematika, yaitu lama 0 bulan (X1), lama 3 bulan (setengah semester) (X2), dan lama 6 bulan (satu semester) (X3). Tabel 1 menunjukkan nilai hasil postes untuk soal yang tergolong sulit data yang diperoleh adalah sebagai berikut:

Tabel 1. Nilai Hasil Postes

\begin{tabular}{cccc}
\hline No & $\mathbf{X}_{\mathbf{1}}$ & $\mathbf{X}_{\mathbf{2}}$ & $\mathbf{X}_{\mathbf{3}}$ \\
\hline 1 & 56 & 62 & 64 \\
2 & 63 & 67 & 69 \\
3 & 64 & 70 & 70 \\
4 & 64 & 73 & 75 \\
5 & 65 & 75 & 78 \\
6 & 67 & 77 & 85 \\
7 & 68 & 80 & 86 \\
8 & 72 & 85 & 88 \\
S & 4.61 & 7.33 & 8.89
\end{tabular}


$\begin{array}{llll}\text { S2 } & 21.27 & 53.70 & 78.98\end{array}$

Uji homogenitas pada uji perbedaan (missal anova) dimaksudkan untuk menguji bahwa setiap kelompok yang akan dibandingkan memiliki variansi yang sama dengan demikian perbedaan yang terjadi dalam hipotesis benar-benar berasal dari perbedaan antara kelompok, bukan akibat dari perbedaan yang terjadi di dalam kelompok. Table 2 merupakan table kerja untuk uji homogenitas penelitian ini.

$\mathrm{H}_{0}: \tau_{1}^{2}=\tau_{2}^{2}=\tau_{R}^{2}$

$\mathrm{H}_{1}$ : salah satu tanda $=$ tidak berlaku (ada yang $\neq$ )

Selanjutnya dibuat table kerja sebagai berikut:

Tabel 2. Tabel Kerja Uji Homogenitas

\begin{tabular}{ccccccc}
\hline Sampel & Df & $\mathbf{1 / d f}$ & $\mathbf{s 2}$ & $\mathbf{l o g} \mathbf{~ s 2}$ & $\mathbf{d f}^{*} \mathbf{s} 2$ & df*$^{*} \log \mathbf{~ s 2}$ \\
\hline 1 & 7 & 0.143 & 21.27 & 1.33 & 148.88 & 9.29 \\
2 & 7 & 0.143 & 53.70 & 1.73 & 375.87 & 12.11 \\
3 & 7 & 0.143 & 78.98 & 1.90 & 552.87 & 13.28 \\
Total & 21 & 0.429 & 153.95 & 4.96 & 1077.62 & 34.69 \\
\hline
\end{tabular}

Menghitung varians gabungan:

$S^{2}=\frac{\Sigma\left(d f \cdot S_{t}^{2}\right)}{\Sigma d f}=\frac{1077,62}{21}=51,315$

$\log S^{2}=\log 51,315=1,710$

Menghitung nilai $\mathrm{B}$ dengan rumus:

$\mathrm{B}=(\Sigma d f) \log S^{2}=21 \cdot 1,710=35,915$

Menghitung $X^{2}$

$X^{2}$ dihitung dengan rumus:

$X^{2}=(\ln 10)\left\{B-\Sigma\left(d f \cdot \log S^{2}\right)\right\}=(2,303)(35,915-34,69)=2,829$

Bandingkan nilai $X_{\text {hitung }}^{2}$ dengan $X_{\text {tabel }}^{2}$ untuk derajat kebebasan (df) 2 pada taraf signifikansi $5 \%(\alpha=0,05)$ diperoleh $X_{t a b e l}^{2}=5,99$. Dengan demikian, harga a $X_{\text {hitung }}^{2} \leq X_{\text {tabel }}^{2}$ sehingga $\mathrm{H}_{0}$ diterima; artinya varians dari ketiga kelompok sampel tersebut adalah homogen.

Analisis varians merupakan suatu cara yang efektif untuk menguji apakah mean dua sampel atau lebih sungguh-sungguh berbeda apa tidak. Penelitian ini ingin menguji lamanya waktu pemberian pemahaman menggunakan filsafat matematika dalam pengajaran matematika terhadap soal matematika yang tergolong kategori sulit. Untuk menguji pengaruh pengajaran matematika dengan menggunakan pemahaman filsafat matematika terhadap nilai soal matematika yang tergolong kategori sulit, di siapkan durasi lama pengajaran matematika menggunakan pemahaman filsafat matematika untuk percobaan yang masing-masing diikuti oleh 8 siswa yang "homogen". Kelompok I diberikan durasi lama 0 bulan, kelompok II durasi lama 3 bulan (setengah 
semester), kelompok III 6 bulan (satu semester). Setelah 1 semester masing-masing kelompok dibandingkan.

Diperoleh tiap kelompok dengan nilai soal sulit seperti di bawah. Tiap kelompok tersebut memang tampak berbeda. Akan tetapi apakah mereka berbeda secara signifikan? Uji-signifikansi yang tepat untuk menjawab pertanyaan itu adalah analisis varians sederhana atau analisis varians satu-arah. Harus dipahami bahwa varians total, atau varians adalah gabungan antara varians antara (between) dan varians dalam (within). Dengan perkataan lain:

Jumlah kuadrat total $=$ jumlah kuadrat between + jumlah kuadrat within,

$$
S S_{\text {total }}=S S_{\text {between }}+S S_{\text {within }}
$$

SS adalah jumlah kuadrat deviasi skor dari mean (the sum of the squares of the deviation scores from the mean). Untuk perhitungan dengan ANOVA kita membutuhkan nilai komponen $S_{\text {total, }}$ SS $_{\text {between }}$ dan SS $_{\text {within }}$ tetapi karena $S S_{\text {total }}=S S_{\text {between }}+S S_{\text {within, kita dapat menghitung dua }}$ komponen sembarang lebih dulu dan selanjutnya dengan mudah kita akan memperoleh komponen yang ketiga. Untuk itu kita dapat menghitung dua yang paling mudah, SS total dan SS between. Jika kita sudah mendapatkan dua komponen tersebut kita akan memperoleh $\mathrm{SS}_{\text {within }}$ dengan mengurangi $\mathrm{SS}_{\text {total }}$ dengan $\mathrm{SS}_{\text {between. }}$

Rumus untuk SS between adalah:

$$
S S_{\text {between }}=\frac{\left(\Sigma X_{1}\right)^{2}}{n_{1}}+\frac{\left(\Sigma X_{2}\right)^{2}}{n_{2}}+\frac{\left(\Sigma X_{3}\right)^{3}}{n_{3}}-\frac{(\Sigma X)^{2}}{N}
$$

Untuk tiga-komponen pertama, yang harus kita kerjakan adalah menjumlahkan nilai masingmasing kelompok, mengkuadratkan totalnya, dan membaginya dengan jumlah individu pada tiap kelompok. Untuk komponen keempat yang harus kita kerjakan adalah menjumlah semua nilai $\left(X_{1}+X_{2}+X_{3}\right)$, mengkuadratkan totalnya, dan membagi dengan total $\mathrm{N}$ atau $\left(\mathrm{n}_{1}+\mathrm{n}_{2}+\mathrm{n}_{3}\right)$. Sebelum kita menghitung mari kita lihat rumus SS total :

$$
S S_{\text {total }}=\Sigma X^{2}-\frac{(\Sigma X)^{2}}{N}
$$

Komponen yang diperlukan yang masih baru bagi kita adalah $\Sigma X^{2}$. Untuk menghitungnnya yang harus kita kerjakan adalah mengkuadratkan setiap nilai (3 kelompok semuanya) dan menjumlahkan kuadratkuadrat untuk masingmasing kelompok. Kita harus ingat bahwa apabila $X$ dan $N$ menyajikan kelompok tertentu diberi tanda subskrip $\left(X_{1}+X_{2}+X_{3}\right.$ dan $n_{1}$ $+\mathrm{n}_{2}+\mathrm{n}_{3}$ ). Jika $X$ dan $\mathrm{N}$ tidak diberi subskrip berarti menyajikan total. Kita sekarang membutuhkan jumlah nilai tiap kelompok dan total untuk semua kelompok serta jumlah kuadrat. Berikut disajikan uji analisis varian dalam tabel 3 . 
Tabel 3. Tabel Kerja Uji Analisis Varians

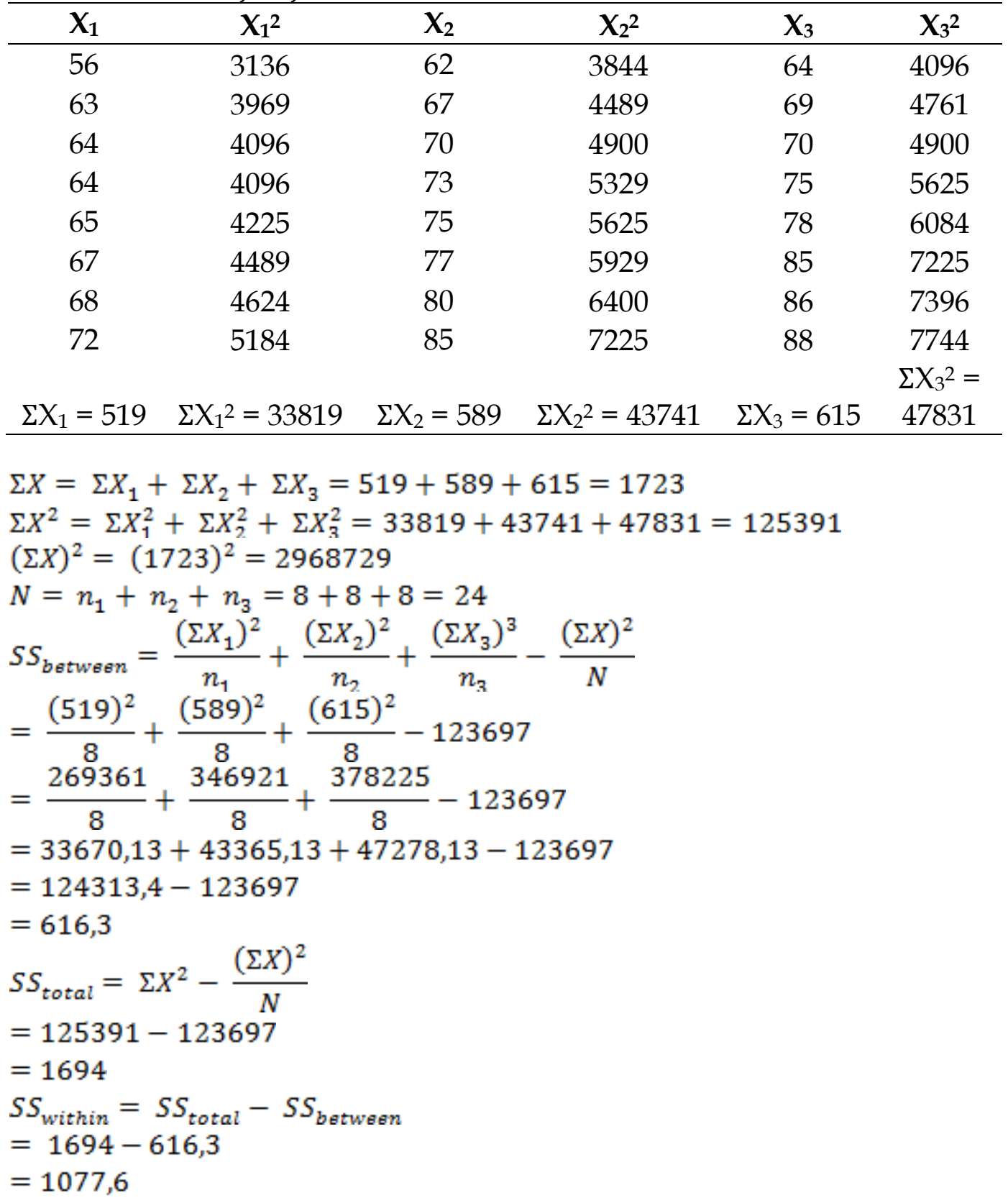

Hal yang perlu diperhatikan di sini adalah bahwa tiap komponen mempunyai rumus tingkat kebebasan (df) masing-masing. Rumus df untuk komponen between adalah $\mathrm{k}-1$, di mana $\mathrm{k}$ adalah jumlah kelompok treatment; jadi $\mathrm{df}_{\text {between }}=\mathrm{k}-1=3-1=2$. Rumus df untuk komponen within adalah $\mathrm{N}-\mathrm{k}$. di mana $\mathrm{N}$ adalah besarnya sampel keseluruhan; jadi $\mathrm{df}_{\text {within }}=\mathrm{N}-\mathrm{k}=24-3=21$. Untuk $\mathrm{df}_{\text {total }}=\mathrm{N}-1=24-1$ $=23$

Sekarang bagaimana dengan kuadrat mean? Kuadrat mean dihitung dengan membagi jumlah masing-masing kuadrat dengan tingkat kebebasannya.

Kuadrat mean $=\frac{\text { Jumlah kuadrat }}{\text { tingkat kebebasan }}$ 
Atau $M S=\frac{s s}{d f}$

Untuk between, kita peroleh:

$M S_{B}=\frac{S S_{B}}{d f_{R}}=\frac{616,3}{2}=308,17$

Untuk within, kita peroleh:

$M S_{W}=\frac{S S_{W}}{d f_{W}}=\frac{1077,6}{21}=51,32$

Sekarang kita menghitung rasio F (perbandingan antara MSB dan MSW)

$F=\frac{M S_{B}}{M S_{W}}=\frac{308,17}{51,32}=6,01$

Dari perhitungan-perhitungan di atas diperoleh ringkasan hasil seperti yang ditunjukkan dalam tabel 4 berikut:

Tabel 4. Tabel Ringkasan Kerja Analisis Varians

\begin{tabular}{ccccc}
\hline Sumber variasi & Jumlah Kuadrat & df & Kuadrat Mean & F \\
\hline Between & 616,3 & 2 & 308,17 & 6,01 \\
Within & 1077,6 & 21 & 51,32 & \\
Total & 1694 & 23 & & \\
\hline
\end{tabular}

Jadi $\mathrm{F}=6,01$, dengan tingkat kebebasan 2 dan 21 . Dengan menetapkan $\mathrm{a}=$ 0,05 , kita mendapatkan nilai $\mathrm{F}$ table sebesar 3,47. Dengan demikian nilai F lebih besar dibandingkan F table. Sehingga hipotesis nol ditolak dan menyimpulkan bahwa ada beda yang signifikan antara mean-mean kelompok.

Pada uji di atas yang ditunjukkan oleh rasio $\mathrm{F}$ adalah hanyalah ada atau tidaknya satu beda yang signifikan entah di mana. Untuk mendapatkan di mana kita akan memakai tes Scheffe melibatkan perhitungan rasio $\mathrm{F}$ untuk tiap pembanding mean. Kalau kita perhatikan rumus di bawah ini, sebenarnya kita telah familiar dengan hampir semua informasi yang dibutuhkan untuk menggunakan uji Scheffe:

$$
F=\frac{\left(M_{1}-M_{2}\right)^{2}}{M S_{W}\left(\frac{1}{n_{1}}+\frac{1}{n_{2}}\right)(k-1)} \quad d f=(k-1)(N-k)
$$

Dari mana kita akan mendapatkan $\mathrm{MS}_{\mathrm{W}}$ ? $\mathrm{MS}_{\mathrm{W}}$ adalah MS dari analisis varians, yaitu 284,29. Tingkat kebebasan juga dari ANOVA, 2 dan 57. Sudah barang tentu rumus di atas adalah untuk perbandingan $\mathrm{M}_{1}$ dan $\mathrm{M}_{2}$. Untuk membandingkan dua mean yang lain kita cukup hanya dengan mengubah $\mathrm{M}_{\mathrm{s}}$ dan $\mathrm{N}_{\mathrm{s}}$. sebelum kita dapat menggunakan uji-Scheffe yang harus kita hitung adalah mean untuk tiap kelompok. Dengan melihat contoh eksperimen diatas, jumlah untuk masingmasing kelompok adalah 519, 589, dan 615.

$M_{1}=\frac{\Sigma X_{1}}{N_{1}}=\frac{519}{8}=64,9$ 
$M_{2}=\frac{\Sigma X_{2}}{N_{2}}=\frac{589}{8}=73,6$
$M_{3}=\frac{\Sigma X_{3}}{N_{3}}=\frac{615}{8}=76,9$

Dengan menerapkan uji-Scheffe pada $\mathrm{M}_{1}$ dan $\mathrm{M}_{2}$

$$
\begin{gathered}
F=\frac{\left(M_{1}-M_{2}\right)^{2}}{M S_{W}\left(\frac{1}{n_{1}}+\frac{1}{n_{2}}\right)(k-1)} \\
=\frac{(64,9-73,6)^{2}}{51,32\left(\frac{1}{8}+\frac{1}{8}\right) 2}=\frac{(-8,8)^{2}}{51,32 \frac{2}{8} 2}=\frac{76,58}{51,32(0,25) 2}=\frac{76,58}{51,32(0,5)}=\frac{76,58}{25,658} \\
=2,98
\end{gathered}
$$

Karena F yang dipersyaratkan agar signifikan adalah 3,47 (untuk $\alpha=0,05$; $\mathrm{df}=2$ dan 21) dan karena 2,98<3,47, kita menyimpulkan bahwa tidak ada beda signifikan antara $\mathrm{M}_{1}$ dan $\mathrm{M}_{2}$.

Dengan menerapkan uji-Scheffe pada $\mathrm{M}_{1}$ dan $\mathrm{M}_{3}$ kita peroleh:

$$
\begin{gathered}
F=\frac{\left(M_{1}-M_{3}\right)^{2}}{M S_{W}\left(\frac{1}{n_{1}}+\frac{1}{n_{3}}\right)(k-1)} \\
=\frac{(64,9-76,9)^{2}}{51,32\left(\frac{1}{8}+\frac{1}{8}\right) 2}=\frac{(-12)^{2}}{51,32 \frac{2}{8} 2}=\frac{144}{51,32(0,25) 2}=\frac{144}{51,32(0,5)}=\frac{144}{25,658} \\
=5,61
\end{gathered}
$$

Karena 5,61 > 3,47, kita menyimpulkan bahwa ada beda yang signifikan antara $\mathrm{M}_{1}$ dan $\mathrm{M}_{3}$. Ingat bahwa karena $\mathrm{N}$ sama dengan contoh sebelumnya, $\mathrm{n}_{1}=\mathrm{n}_{2}=\mathrm{n}_{3}$ maka penyebutnya sama.

Dengan cara yang sama diperoleh perbandingan antara $\mathrm{M}_{2}$ dan $\mathrm{M}_{3}$ dan kita peroleh:

$$
\begin{aligned}
& F=\frac{\left(M_{2}-M_{3}\right)^{2}}{M S_{W}\left(\frac{1}{n_{2}}+\frac{1}{n_{3}}\right)(k-1)} \\
& =\frac{(73,6-76,9)^{2}}{51,32\left(\frac{1}{8}+\frac{1}{8}\right) 2}=\frac{(-3,3)^{2}}{51,32 \frac{2}{8} 2}=\frac{10,56}{51,32(0,25) 2}=\frac{10,56}{51,32(0,5)}=\frac{10,56}{25,658} \\
& \quad=0,41
\end{aligned}
$$

Karena 0,41 < 3,47, kita menyimpulkan bahwa tidak ada beda yang signifikan antara $\mathrm{M}_{2}$ dan $\mathrm{M}_{3}$. Kesimpulanya, kelompok III secara signifikan mempunyai penampilan lebih baik dibanding kelompok I dan itulah satu-satunya beda yang signifikan. Meskipun kelompok II berpenampilan lebih baik daripada kelompok I $\left(\mathrm{M}_{1}=64,9\right.$ dan $\left.\mathrm{M}_{2}=73,6\right)$ beda sebesar 8,8 belum merupakan suatu beda yang signifikan. Sehingga pengajaran matematika dengan menggunakan pemahaman filsafat 
matematika terhadap nilai soal matematika yang tergolong kategori sulit, akan menghasilkan sesuatu yang signifikan jika setidaknya diajarkan dalam waktu 1 semester.

Uji Scheffe digunakan juga untuk membandingkan kombinasi dari mean-mean. Dalam eksperimen ini kelompok I adalah kelompok control dan kita ingin membandingkan mean kelompok I dengan mean kombinasi kelompok II dan III. Pertama kali kita harus menggabungkan mean-mean kelompok II dan kelompok III sebagai berikut:

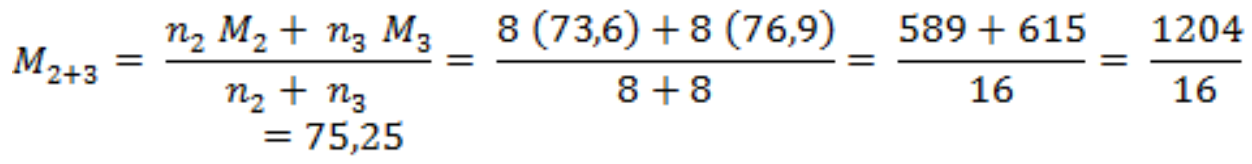

Sudah barang tentu karena $\mathrm{N}_{2}=\mathrm{N}_{3}$, kita dengan mudah mencari ratarata mean sebagai berikut:

$M_{2+3}=\frac{M_{2}+M_{3}}{2}=\frac{73,6+76,9}{2}=75,25$

Selanjutnya kita menghitung rasio $\mathrm{F}$ dengan $\mathrm{M}_{1}=64,9$ dan mean digabung $\mathrm{M}_{2+3}=75,25$ :

$$
\begin{aligned}
& F=\frac{\left(M_{1}-M_{2+3}\right)^{2}}{M S_{W}\left(\frac{1}{n_{1}}+\frac{1}{n_{2+3}}\right)(k-1)} \\
& =\frac{(64,9-75,25)^{2}}{51,32\left(\frac{1}{8}+\frac{1}{16}\right)_{2}}=\frac{(-10,4)^{2}}{51,32(0,13+0,06) 2}=\frac{107,64}{51,32(0,19) 2}=\frac{107,64}{19,24} \\
& =5,59
\end{aligned}
$$

Karena 5,59 $>3,47$, kita menyimpulkan bahwa ada beda yang signifikan antara M1 dan M2+3. Dengan perkataan lain, kelompok eksperimen secara signifikan bepenampilan lebih baik dibandingkan kelompok control.

\section{KESIMPULAN}

Berdasarkan hasil penelitian yang telah diuraikan, maka kesimpulan dari penelitian eksperimen ini adalah (1) ada beda yang signifikan antara mean-mean kelompok, yaitu kelompok 1 sebagai variabel control, kelompok 2 sebagai variabel eksperimen dengan lama setengah semester pengajaran matematika dengan model filsafat matematika dan kelompok 3 sebagai variabel eksperimen dengan lama satu semester pengajaran matematika dengan model filsafat matematika. (2) kelompok III secara signifikan mempunyai penampilan lebih baik dibanding kelompok I dan itulah satu-satunya beda yang signifikan. Meskipun kelompok II berpenampilan lebih baik daripada kelompok I $\left(\mathrm{M}_{1}=64,9\right.$ dan $\left.\mathrm{M}_{2}=73,6\right)$ beda sebesar 8,8 belum merupakan suatu beda yang signifikan. (3) kelompok III secara signifikan mempunyai penampilan lebih baik 
dibanding kelompok I dan itulah satu-satunya beda yang signifikan. Meskipun kelompok II berpenampilan lebih baik daripada kelompok I $\left(\mathrm{M}_{1}=64,9\right.$ dan $\left.\mathrm{M}_{2}=73,6\right)$ beda sebesar 8,8 belum merupakan suatu beda yang signifikan. (4) ada beda yang signifikan antara M1 dan M2+3. Dengan perkataan lain, kelompok eksperimen secara signifikan bepenampilan lebih baik dibandingkan kelompok control.

\section{DAFTAR RUJUKAN}

Alisah, Evawati \& Dharmawan, Eko Prasetyo. (2007). Filsafat Dunia Matematika: Pengantar untuk Memaham Konsep-Konsep Matematika. Jakarta: Prestas Pustakaraya.

Aminah, S., Wijaya, T.T., \& Yuspriyanti, D. (2018). Analisis kemampuan komunikasi matematis siswa kelas viii pada materi himpunan. Jurnal Cendekia: Jurnal Pendidikan Matematika, 2(1), 15-22.

Dwidarti, U., Mampouw, Lygia, H. \& Setyadi, D. (2019). Analisis kesulitan siswa dalam menyelesaikan soal cerita pada materi himpunan. Jurnal Pendidikan Matematika, 3(2), 315-322.

Fauzi, A., Waluya, B., \& Masrukan. (2019). Pembelajaran matematika dengan pendekatan realistic mathematics education (RME) berbasis soal openended untuk meningkatkan komunikasi. Phenomenon, 9(1), 87-98.

Fraenkel, J.R., Wallen, N.E., \& Hyun, H.H. (2012). How to Design and Evaluate Research in Education. United States (New York): McGraw-Hill Companies. Inc.

Halim,F., \& Rasidah, N. (2019). Analisis kesalahan siswa dalam menyelesaikan (analysis of student errors in resolcing the problem of Gauss: Jurnal Pendidikan Matematika, 02(01), 35-44.

Irmawati, Rukli, \& Bharllah. (2019). Pengembangan perangkat pembelajaran matematika menggunakan metode discovery learning berbasis grander di sekolah dasar. Edumaspul: Jurnal Pendidikan, 3(2), 127-139.

Lestari, Karunia Eka \& Yudhanegara, Mokhammad Ridwan. (2015). Penelitian Pendidikan Matematika. Bandung: PT Refika Aditama.

Lukiastuti, Fitri \& Hamdani, Muliawan. (2021). Statistika Non Parametris. Yogyakarta: Center of Academic Publishing Service.

Martini, S., \& Al, E. (2018). Pengaruh pendekatan realistic terhadap kemampuan komunikasi dan self confidence siswa Smp. Jurnal Pembelajaran Matematika Inovatif, 1(2), 149-156.

Yuharsono. (2018). Pengembangan perangkat pembelajaran aritmetika social dengan pendekatan matematika realistic dan model belajar kooperatif tipe stad. Penelitian Matematika dan Pendidikan Matematika, 1(2), 92106.

Zakiah, N.e., Sunaryo, Y., \& Amam, A. (2019). Implementasi pendekatan kontekstual pada model pembelajaran berbasis masalah berdasarkan langkah-langkah polya. Teorema: Teori dan Riset Matematika, 4(2), 111120.

Zanthy, L.S. (2016). Pengaruh motivasi belajar ditinjau dari latar belakang pilihan jurusan terhadap kemampuan berpikir kritis mahasiswa di stkip siliwangi bandung. Teorema: Teori dan Riset Matematika, 1(1), 47-54. 